\title{
La tuberculosis después del descubrimiento de Koch
}

\author{
WALTER LEDERMANN D.
}

\author{
Tuberculosis after Koch's discovery
}

En dos ocasiones anteriores me he referido en estas notas a la historia de la tuberculosis: la primera vez, al comentar la rivalidad entre franceses y alemanes en su carrera por descubrir a la bacteria causante, y la segunda, al relatar los hechos precedentes al descubrimiento de Koch. En esta tercera oportunidad quiero referirme a sucesos posteriores a este hallazgo.

Otro sabio que en esta historia sufrió, como Villemin, del despojo y del olvido, fue Paul Ehrlich, el autor de la tinción que posibilitó el método diagnóstico de la baciloscopía. Koch empleaba azul de metileno alcalino, seguido por la tinción de Bismarck, método al cual, de acuerdo a Loeffler, llegó sólo por accidente. Ehrlich, en cambio, fundamentó su método en el carácter ácido-alcohol resistente a la decoloración, propio del bacilo tuberculoso, para evidenciar el cual utilizó ácido nítrico y tiñó con violeta de genciana o fucsina, en presencia de anilina disuelta en agua. Ehrlich comunicó su descubrimiento el 1 de mayo de 1882, fecha en que comienza la insólita historia de la tinción “de Ziehl-Neelsen", a la cual ya nos hemos referido en una ocasión anterior (Colones y Pinzones de la Microbiología). Franz Ziehl, un bacteriólogo alemán (1857-1926), prácticamente no aportó nada : propuso utilizar ácido carbólico en lugar de anilina, alternativa que ya había mencionado el propio Ehrlich. En cuanto a Karl Adolf Neelsen, un patólogo alemán que tuvo una vida muy breve (1854-1894), cambió la genciana por fucsina -también una alternativa de Ehrlich- y el ácido nítrico por sulfúrico. Ni Ziehl ni Neelsen hicieron publicación alguna ni se atribuyeron autoría: el nombre de la tinción surgió de una simple nota al pie de una página, en una publicación que Johne hiciera en 1885. Heinrich Albert Johne, también un patólogo alemán de la época (1839-1910), fue el descubridor del llamado Mycobacterium paratuberculosis, causante de una diarrea crónica del ganado; tanto el bacilo como la enfermedad perpetúan el nombre de quien, aparentemente por no molestarse en buscar una referencia, atribuyó la idea original a dos modificadores de ella. ¡En qué frágiles fundamentos puede construirse una nombradía eterna!.

Koch reconoció que su propia coloración quedaba superada por la de Ehrlich y, buscando recuperar el crédito después del fracaso terapéutico de su Heilmittel -que había permitido un violento y triunfal contragolpe de Virchow, al certificar que su inyección aumentaba la intensidad de la lesión tuberculosa- causó sensación en 1901 con su conferencia en el Saint James Hall, durante el Congreso Británico de Tuberculosis, al demostrar que los bacilos humano y bovino no eran idénticos. En colaboración con Schütz comprobaron que el bacilo humano no causaba tuberculosis al ganado. No eran novedad estas diferencias, en parte establecidas por Villemin y Teobald Smith, pero igual hicieron efecto y la popularidad de Koch revivió y pudo retomar su corona de Rey de la Tuberculosis, quedando establecida la separación actual entre las especies $M$. tuberculosis y M. bovis. Para la comodidad de nuestra historia, las consideraremos un complejo, siguiendo la moda actual.

Por su parte, Behring creía que el bacilo bovino se transformaba en humano al parasitar al hombre, lo que no pudo demostrar. Luego de establecer claramente la distinta identidad de ambos bacilos, Koch cometió otro error al sostener que el bovino casi no producía tuberculosis en el hombre, afirmación que llevó a la formación en Gran Bretaña de una Royal Comission para estudiar el problema. Fruto del trabajo de esta comisión y tras el análisis de numerosas autopsias en niños menores de trece años, F. Griffith y S. Griffith publicaron en 1911 que el bacilo bovino aportaba el $16,8 \%$ de los fallecimientos por tuberculosis.

Entre los errores curiosos de la época, merece mencionarse el de las "formas filtrables", debido mayormente a observaciones de Calmette. Éste -y algunos otros- postularon la existencia de formas ultramicroscópicas, que atravesaban las bujías Barkefield y Chamberlain, infiriendo de ello que podrían atravesar la placenta y llegar al feto (Calmette, 1926; Fontes, 1910; Vaudremer, 1921; Haudoroy, 1923). Sea cual fuere el error en el diseño de sus experimentos, la lista de quienes demostraron su inexistencia fue muchísimo mayor, en Inglaterra, Alemania, Italia y Estados Unidos: ;otra vez los franceses perdían! La revancha, sin embargo, habría de llegar pronto, con ocasión del desarrollo de una vacuna.

Desde los primeros trabajos de Koch se habían descrito cepas atenuadas: la K1 del mismo Koch, la cepa aviaria de Nocard y la "BB", que debió ser "BBB", pues fue aislada por Burchard y luego descrita por Borrel y Boez. Por su parte, los alemanes habían vacunado terneros, Behring con su "bovovacuna" (cepa bovina) y Koch con su Tauruman (cepa humana). El alemán Friedrich Franz Friedmann 
luchó muchos años por imponer una vacuna, curativa y preventiva (¿deberíamos llamarla "FFF"?), preparada a partir de una cepa aislada de una tortuga gigante, fallecida en el Aquarium de Berlín en 1902; la formulación francesa (¡cuándo no!) fue la ART, igualmente un fracaso.

Los franceses Albert Leon Charles Calmette (18631933) y Camille Guérin (1872- 1961), también comenzaron sus trabajos vacunando terneros por vía oral con un bacilo virulento, obteniendo una inmunidad que duraba 8 meses, éxito que los estimuló a buscar una vacuna aplicable al hombre. En 1906 iniciaron un cultivo continuo con una cepa bovina, utilizando un medio biliado glicerinado al 5\%. Al cabo de cuatro años dicha cepa había perdido virulencia para el ganado y para el cobayo; luego de 230 traspasos ya era avirulenta para todos los animales domésticos, propiedad que mantenía al ser transferida a medios biliados cada diez subcultivos. Se hicieron ensayos sucesivos en cobayos, conejos, ganado y monos, hasta llegar en 1921 a su primera aplicación al ser humano, vacunando a 120 recién nacidos con tres dosis orales de $2 \mathrm{mg}$ cada una, durante las dos primeras semanas de vida. Tres años después, en 1924, se iniciaba la administración oficial en Francia; hoy en día, desaparecida la antivariólica, la BCG es la vacuna más antigua en uso... y la más discutida desde sus mismos inicios. Una extraña y cruel burla del destino hizo que esta vacuna francesa causara un desastre en Alemania. En 1930, en la ciudad de Lübeck, 249 recién nacidos recibieron una vacuna BCG que no era tal, pues había sido erróneamente preparada con una cepa virulenta de Mycobacterium tuberculosis, falleciendo 73 de ellos. Dice la leyenda que, a raíz de esto, tres años después y en su lecho de muerte, Calmette habría rogado encarecidamente que no siguiera utilizando su vacuna.

Por su parte, Koch, desaparecido en 1910, no alcanzó a conocer esta tremenda catástrofe, pero... ¡qué hubiera dicho! Antes de morir, había dejado muchos estudios bien encaminados, fiel a su creencia que "la felicidad consiste en la pasión por la investigación" . Así, había purificado su tuberculina en 1897, con la cual se efectuarían todas las pruebas diagnósticas: lo que llamó "la reacción de depósito". Clemens Freiherr von Pirquet, un pediatra austríaco (1874-1929), trocó esta inyección subcutánea por una simple escarificación en 1907; ya antes, en 1903, Kligmuller la había hecho intradérmica, método mejorado por Mendel y luego en 1908 por Charles Mantoux, un médico francés (1877-1947), año en que Wolff propuso una peligrosa instilación ocular. También inició Koch el desarrollo de los medios de cultivo, usando suero de bovino congelado, que luego Teobald Smith intentara cambiar por suero de perro, hasta que Dorset impusiera en 1902 el huevo de gallina: con el agregado de otros nutrientes y de algunos inhibidores se llegaría al actual medio de Löwenstein y Jensen (asparagina, papa, glicerol, sulfato y citrato de magnesio, verde de malaquita).

La historia del bacilo de Koch se cierra, por el momento, con una última controversia histórica, la de Waksman y Schatz sobre el descubrimiento de la estreptomicina. Antes del descubrimiento de Koch, el tratamiento tendía a detener la consunción, para lo cual se recurría a determinados climas, ejercicios y alimentos. En su Historia Natural, publicada durante el siglo de Augusto, Plinio el Viejo suministra un ejemplo de tales dietas: "Un hígado de lobo, hervido en vino leve; el tocino de una cerda alimentada con hierbas..." Pero desde antiguo lo más recomendado era el tratamiento lácteo, utilizando leche de vaca, de cabra, de camello, de burra, de elefante y, muy especialmente, humana. Petrus Forestus, en el siglo XVI, recomendaba a sus pacientes que mamasen de una mujer joven, ubicándose a los costados de ella, para poder succionar continuamente... En este mismo sentido, también se estimaba beneficioso beber sangre de toro (o de tortuga, que para todo hay gustos). En cuanto al clima, era recomendable elegir la alta montaña, pero también existían inhalaciones específicas y más concentradas, comprendiendo las de humo obtenido al quemar estiércol de vaca (Plinio), de algas marinas (Laennec), humo de resina o de brea (en un periódico de Nantucket, 1821). La estadía en alta montaña se complementaba con una dieta muy abundante, con numerosas comidas diarias, como lo describe minuciosa y elegantemente Thomas Mann en Der Zauberberg. Entre los ejercicios, Sydenham recomendaba montar diariamente a caballo, en cuyo caso uno podría argumentar que el mayor ejercicio corría por cuenta del caballo.

Descubierto el agente causal de la tuberculosis, comenzaron los ensayos in vitro e in vivo con distintos inhibidores del bacilo. De un texto de Colbert de Cambo, Le traitment de la tuberculose pulmonaire en clientele, publicado en París en 1923, podemos extraer una larga lista de increíbles sustancias, que menciona luego de analizar el clima y las curas de reposo y de trabajo. Al comenzar su análisis, señala sabiamente que la eficacia de estos "medicamentos" es "parcial, incompleta, aleatoria y siempre insuficiente", frase que está subrayada y que atribuye a Kuss. La lista comprende calcio, alcanfor, arsénico, fierro, yodo, creosota, guayacol, gomenol, tanino, cobre, manganato cálcico-potásico, tierras raras, lecitina, colesterina, etc... Pero si estas sustancias iban por vía oral o intramuscular, mucho peor eran las inyecciones intratraqueales de antisépticos, como esencia de vainilla, aceite a la esencia de mirto, aceite de oliva guayacolado... Había preparados famosos, con nombres sonoros: aurocantán, crisolgán $\mathrm{y}$ cianocuprol. La sanocrisina, estudiada in vitro frente al bacilo por Möllgaard en 1924, llevaba un 37, $4 \%$ de oro y era más cara que cualquiera de los antibióticos actuales; felizmente, Amberson la derribó en 1931 mediante un estudio comparativo in vivo.

El advenimiento de los quimioterápicos y antibióticos hizo nacer esperanzas de encontrar un medicamento activo. De los primeros, como el conteben, las totalinas $\mathrm{T}$ y $\mathrm{M}$, etc, sólo triunfarían el PAS y la isoniacida. De los segundos, la historia exitosa comienza en septiembre de 1943, cuando el equipo de Selman Waksman, que ya había aislado una droga activa frente al bacilo de Koch, la estreptotricina, descartada pronto por tóxica, des- 
cubrió la estreptomicina. El orden en la primera publicación de 1944 es: Schatz, Bugie, Waksman. El mismo Waksman escribe: "Sus efectos como inhibidora del crecimiento sobre el organismo de la tuberculosis fueron rápidamente establecidos (Schatz y Waksman, 1944) “. La gloria y el Premio Nobel recayeron sobre Waksman, dejando a Schatz en la oscuridad, pero no en el silencio, pues harto reclamó su crédito. En su libro The conquest of the tuberculosis, Waksman se embarca en una minuciosa explicación, tendiente a demostrar que es imposible definir "quien aisló del suelo realmente el cultivo productor de la estreptomicina", partiendo desde un chacarero que llevó al patólogo aviar un pollo enfermo, en septiembre de 1943, patólogo que tomó un cultivo, luego contaminado accidentalmente con un hongo... Este hongo fue enviado a Waksman, quien lo entregó a uno de sus "estudiantes graduados"... $\mathrm{Y}$ así sigue una larga historia, que concluye cinco meses después: "en enero de 1944, Schatz, Bugie y yo mismo anunciamos el descubrimiento en un artículo". No puede estar más claro: fue Schatz, quien ahí desaparece del escenario, para que Waksman tome las riendas del trascendente descubrimiento, que le proporcionaría una gloria similar a la que tuvo en su momento Koch con su bacilo.

Albert Schatz estuvo en Chile en los años sesentas, trabajando en la planta de antibióticos del Instituto Bacteriológico, donde tuvimos oportunidad de conocerlo. Nos dejó como souvenir un apartado de la publicación que hizo aquí, en castellano y bajo el auspicio de la Facultad de Química y Farmacia de la Universidad de Chile, acerca del flúor y la salud dental, donde muestra su virulento estilo de polemista científico, todo lleno de citas irónicas, de exclamativos y de subrayados en mayúsculas. Para dar una muestra de su estilo, el artículo se inicia con una frase de Winston Churchill, destacada en cursiva : La mayor lección de la vida es darse cuenta de que hasta los tontos tienen razón a veces.

¿Y los franceses? Contraatacaron con la flavoricina, aislada de Aspergillus flavus, que se desvaneció en la nada luego de sus efímeros éxitos iniciales.

El bacilo de Koch supo defenderse de la estreptomicina y generar una lenta pero sostenida resistencia. Otros quimioterápicos y antibióticos fueron apareciendo, hasta culminar con el descubrimiento de la rifampicina por Piero Sensi en Italia, en 1965, que pareció inflingir al Mycobacterium tuberculosis un golpe decisivo.

Por ahora, dejaremos aquí la inconclusa historia de este célebre microorganismo, cortándola con un poema de Sir Robert Hutchinson, que tomamos del apartado que nos legara Schatz:
Del fervor excesivo por lo nuevo

y desprecio de lo que es viejo;

de anteponer el conocimiento a la sabiduría,

la ciencia al arte

y el amaño al sentido común;

de tratar pacientes como casos,

de hacer la cura de la dolencia

más penosa que el sufrimiento de ella,

¡líbranos, Señor!

\section{Bibliografía}

1.- Bulloch W. Bacillus tuberculosis, History. En : Medical Research Council's A system of bacteriology in relation to medicine. His Majesty's Stationary Office, London 19930; V: 151-6.

2.- Celso A C. Los ocho libros de la medicina. Editorial Iberia, Barcelona, 1966.

3.- Colbert de Cambo C. Le traitement de la tuberculose pulmonaire en clientele. A. Maloine et fils, Paris, 1923.

4.- Haggard, H. El médico en la historia, 4a edición, Sudamericana, Buenos Aires, 1952.

5.- Koch R. La etiología de la tuberculosis y otros escritos. Eudeba, Buenos Aires, 1965.

6.- Lain Entralgo P. Historia de la Medicina. Salvat, Barcelona, 1978 .

7.- Ledermann W. Franceses y alemanes tras la etiología de la tuberculosis. Rev Chile Infect 1994; 11: 239-42.

8.- Ledermann W. La tuberculosis antes del descubrimiento de Koch. Rev Chile Infect 1996; 13 (4): 239-41.

9.- Ledermann W. En los 500 años del descubrimiento de América: Colones y Pinzones de la Microbiología. Rev Chile Infect 1993; 10: 107-9.

10.- Lombard H C. Traité de climatologie médicale. J Balliére et fils, Paris, 1877.

11.- Mann T. La montaña mágica. Ediciones Ercilla, Santiago, 1950.

12.- Menzel R. Triunfo de la medicina. Ediciones Peuser, Buenos Aires, 1952.

13.- Paracelso. Las plantas mágicas. Ediciones 29, Barcelona 1997.

14.- Schatz A, Bugie E, Waksman S. Sytreptomycin, a substance exhibiting antibiotic activity against Grampositive and Gram-negative bacteria. Proc Soc Exper Biol Med 1944; 55: 66-9.

15.- Schatz A, Waksman S. Effect of streptomycin and other antibiotic substances upon Mycobacterium tuberculosis and related organisms. Proc Soc Exper Biol Med 1944; 57: 244-48.

16.- Schatz A. Elementos traza, nutrición, flúor y salud dental. La Tribuna Odontológica 1965; XLIX (1012): 3-12.

17.- Sergent E. Traité de Pathologie Médicale et de Thérapeutique appliqué, Vol XVII. Tuberculose, tome 1. A. Maloine et fils, París, 1920.

18.- Tyndall J. Les microbes. Librairie F. Savy, París, 1882.

19.- Waksman S. La conquista de la tuberculosis, E. HobbsSudamericana, Buenos Aires, 1968. 